\title{
A study to evaluate a correlation between various Gray Scale parameters and period of gestation
}

\author{
Nancy Chakarvarty ${ }^{1 *}$, Kumkum Srivastav ${ }^{2}$, Sachin Khanduri $^{3}$
}

\begin{abstract}
${ }^{1}$ Department of Obstetrics and Gynecology, Maharaja Agrasen Medical College, Agroha, Hisar, Haryana, India ${ }^{2}$ Department of Obstetrics and Gynecology, ${ }^{3}$ Department of Radiodiagnosis, Eras Lucknow Medical College, Lucknow, Uttar Pradesh, India
\end{abstract}

Received: 09 April 2018

Accepted: 02 May 2018

\section{*Correspondence:}

Dr. Nancy Chakarvarty,

E-mail: nancychakarvarty@yahoo.com

Copyright: () the author(s), publisher and licensee Medip Academy. This is an open-access article distributed under the terms of the Creative Commons Attribution Non-Commercial License, which permits unrestricted non-commercial use, distribution, and reproduction in any medium, provided the original work is properly cited.

\begin{abstract}
Background: Accurate prediction of the gestational age (GA) is very important in the management of obstetric patients for planning a timely and uneventful outcome. Fetuses with intrauterine growth restriction (IUGR) are at high risk for poor short- and long-term outcome. The present study was conducted with the aim to evaluate a correlation between various Gray Scale parameters and period of gestation.

Methods: A total of 100 clinically suspected FGR subjects were enrolled for the present study. Women with singleton pregnancies with fundal height being less than the period of gestation by 4 weeks or more and certainty of last menstrual period with previous 3 menstrual cycles were included in the present study. Ultrasound examination both by Gray Scale USG carried out serially every three weeks starting from 30 weeks till delivery. Chi-square test was used to compare the proportions while Independent Samples " $t$ "-test was used to compare the parametric variables in two groups. Receiver-Operator curve analysis was performed to find out appropriate cut-off points for prediction of FGR.

Results: Diagnostic accuracy of TCD/AC ratio as a marker of FGR was found to be $77 \%$, of HC/AC ratio was found to be $93 \%$ and FL/AC ratio was $59 \%$.

Conclusions: Among three gray scale parameters being assessed, HC/AC ratio at 36 weeks was observed to be having $98.5 \%$ sensitivity and $82.9 \%$ specificity, thus showing the highest diagnostic accuracy (93\%). However, from the point of view of early detection, TCD/AC ratio was found to be most efficient with $81.5 \%$ sensitivity and $68.6 \%$ specificity and overall diagnostic accuracy of $77 \%$. Precision of Grayscale findings at later stage (36 weeks) are higher.
\end{abstract}

Keywords: FL/AC ratio, Gray scale USG, HC/AC ratio, TCD/AC ratio

\section{INTRODUCTION}

Accurate prediction of the gestational age (GA) is very important in the management of obstetric patients for planning a timely and uneventful outcome. ${ }^{1}$ Fetuses with intrauterine growth restriction (IUGR) are at high risk for poor short- and long-term outcome. ${ }^{2}$ Monitoring fetal growth and assessing its predictors have important place in antenatal care management. ${ }^{3}$ Biparietal diameter, head circumference, abdominal circumference and femur length (FL) are considered reliable predictors and are used as routine parameters.

These parameters are helpful in the estimation of fetal age in patients whose fundal height on abdominal examination does not corresponding to the last menstrual period, in cases where the measurement is not reliable 
femoral length and humeral length allow reliable estimation of fetal age. ${ }^{1}$

Accurate prediction of gestational age (GA) and birth weight $(\mathrm{BW})$ is clinically important. Up to $10 \%$ of all liveborn babies and at least $30 \%$ of those of low birth weight suffer from fetal growth restriction; their perinatal mortality is four to 10 times higher than that of normally grown babies. Poor growth also exposes the fetus and the newborn to perinatal complications like neurodevelopmental disability. ${ }^{3}$

Although there are many underlying etiologies, IUGR resulting from placental insufficiency is most relevant clinically because outcome could be altered by appropriate diagnosis and timely delivery. A diagnostic approach that aims to separate IUGR resulting from placental disease from constitutionally small fetuses and those with other underlying etiologies (e.g., aneuploidy, viral infection, nonaneuploid syndromes) needs to integrate multiple imaging modalities. ${ }^{2}$

The present study was conducted with the aim to evaluate a correlation between various Gray Scale parameters and period of gestation.

\section{METHODS}

A total of 100 clinically suspected FGR subjects who reported to the Departments of Obstetrics and Gynecology, Radiology and Pediatrics, Era's Lucknow Medical College and Hospital, Lucknow were enrolled for the purpose of this study after informed consent in patient's language This study was approved by Institutional Review Board and Institutional Ethical Committee. The present study was carried over a period of eighteen months. Women with singleton pregnancies with fundal height being less than the period of gestation by 4 weeks or more 4 and certainty of last menstrual period with previous 3 menstrual cycles (after withdrawal of oral contraceptive pills) were included in the present study. Patients with congenital malformations of the fetus were excluded from the study.

A detailed history and examination was done. Ultrasound examination by Gray Scale USG was carried out serially every three weeks starting from 30 weeks till delivery.

Procedure of Gray Scale Ultrasonography: The patient was advised to lie on her back. A film gel was applied to the abdomen to improve the conduction of sound. A transducer was then moved slowly over the abdomen, and the echoes of sound waves were recorded. The following parameters were recorded and measured by Hadlock's method incorporated in the USG software.

- TCD/AC ratio

- HC/AC ratio

- $\mathrm{FL} / \mathrm{AC}$ ratio

After collection of data the clinical data was correlated with radiological findings using Statistical Package for Social Sciences Version 15.0. Chi-square test was used to compare the proportions while Independent Samples " $t$ "test was used to compare the parametric variables in two groups. Receiver-Operator curve analysis was performed to find out appropriate cut-off points for prediction of FGR.

\section{RESULTS}

A significant difference between FGR and TCD/AC ratio was seen (Table 1). It was seen that at all time intervals, the mean TCD/AC ratio in FGR group was significantly higher as compared to no FGR group.

Table 1: TCD/AC Ratio in two groups at different time intervals.

\begin{tabular}{|lllllllll|}
\hline Time & \multicolumn{2}{c}{ Non-FGR Group $(\mathbf{n}=\mathbf{3 5})$} & \multicolumn{2}{c}{ FGR Group $(\mathbf{n = 6 5})$} & \multicolumn{2}{c|}{ Statistical significance } \\
interval & Mean & SD & $\mathbf{9 5 \%}$ CI & Mean & SD & $\mathbf{9 5 \%}$ CI & "t" & "p" \\
\hline 30 week & 12.87 & 2.82 & $11.90-13.84$ & 15.46 & 2.15 & $14.92-15.99$ & 5.127 & $<0.001$ \\
\hline 33 week & 13.09 & 2.75 & $12.15-14.04$ & 15.52 & 2.09 & $15.01-16.04$ & 4.959 & $<0.001$ \\
\hline 36 week & 13.17 & 2.67 & $12.26-14.09$ & 15.56 & 1.95 & $15.07-16.04$ & 5.105 & $<0.001$ \\
\hline 39 week & 13.19 & 2.71 & $12.26-14.13$ & 15.59 & 2.09 & $15.07-16.11$ & 4.923 & $<0.001$ \\
\hline
\end{tabular}

In non-FGR group, the mean $\mathrm{TCD} / \mathrm{AC}$ ratio was found to be $12.87 \pm 2.82$ (95\% CI 11.90-13.84), 13.09 $\pm 2.75(95 \%$ CI $12.15-14.04), 13.17 \pm 2.67$ (95\% CI 12.26-14.09) and $13.19 \pm 2.71$ (95\% CI 12.26-14.13) at $30 \mathrm{wk}, 33 \mathrm{wk}, 36$ wk and 39 wk respectively. In contrast in FGR group, the mean TCD/AC ratio was found to be $15.46 \pm 2.15$ (95\% CI 14.92-15.99), $\quad 15.52 \pm 2.09 \quad(95 \%$ CI $15.01-16.04)$,
15.56 \pm 1.95 (95\% CI 15.07-16.04) and 15.59 \pm 2.09 (95\% CI 15.07-16.11) at $30 \mathrm{wk}, 33 \mathrm{wk}, 36 \mathrm{wk}$ and $39 \mathrm{wk}$ respectively. Thus, we can clearly see that in the FGR group, the $95 \%$ confidence interval's lower limit was always higher than that of non-FGR group. The 30-wk TCD/AC ratio was regressed with the help of Receiver Operator Curve analysis to differentiate between nonFGR and FGR groups. A poor correlation ( $\mathrm{r}=0.039$; 
$\mathrm{p}=0.437$ ) was seen between gestational age and TCD/AC ratio.

Table 2: Receiver operator curve analysis to find out appropriate cut-off of TCD/AC ratio for FGR detection.

\begin{tabular}{|c|c|c|c|c|}
\hline \multirow[t]{2}{*}{ Area } & \multirow[t]{2}{*}{$\begin{array}{l}\text { Std. } \\
\text { Error(a) }\end{array}$} & \multirow[t]{2}{*}{$\begin{array}{l}\text { Asymptotic } \\
\text { Sig.(b) }\end{array}$} & \multicolumn{2}{|c|}{$\begin{array}{l}\text { Asymptotic } 95 \% \\
\text { confidence } \\
\text { interval }\end{array}$} \\
\hline & & & Lower & Upper \\
\hline 0.762 & 0.055 & $<0.001$ & 0.654 & 0.871 \\
\hline
\end{tabular}

a. Under the nonparametric assumption; $b$. Null hypothesis: true area $=0.5$

The analysis of diagnostic efficacy of TCD/AC ratio to detect FGR was checked in the present series and the results have been shown in Table 2 . The area under curve was found to be 0.762 . The cut-off value above 14.18 was regressed to be $81.5 \%$ sensitive and $68.6 \%$ specific (Table 2).
Table 3: Diagnostic efficacy of TCD/AC ratio as a marker of FGR (Cut-off 14.18).

\begin{tabular}{|c|c|c|c|c|}
\hline \multirow{2}{*}{$\begin{array}{l}\text { TCD } \\
\text { Ratio } \\
>14.18\end{array}$} & \multicolumn{4}{|l|}{ Outcome } \\
\hline & $\begin{array}{l}\text { FGR } \\
(n=65)\end{array}$ & $\begin{array}{l}\text { No FC } \\
(n=35\end{array}$ & & Total \\
\hline Positive & 53 & 24 & & 36 \\
\hline Negative & 12 & 11 & & 64 \\
\hline Total & 65 & 35 & & 100 \\
\hline Sensitivity & Specificity & PPV & NPV & $\begin{array}{l}\text { Diagnostic } \\
\text { accuracy }\end{array}$ \\
\hline 81.5 & 68.6 & 82.8 & 66.7 & 77.0 \\
\hline
\end{tabular}

On evaluation, the cut-off value of 14.18 was found to be $81.5 \%$ sensitive and $68.6 \%$ specific with a positive predictive value of $82.8 \%$ and a negative predictive value of $37.5 \%$ (Table 3 ). The diagnostic accuracy was found to be $77 \%$.

Table 4: HC/AC ratio in two groups at different time intervals.

\begin{tabular}{|c|c|c|c|c|c|c|c|c|}
\hline \multirow{2}{*}{ Time interval } & \multicolumn{3}{|c|}{ Non-FGR Group $(n=35)$} & \multicolumn{3}{|c|}{ FGR Group (n=65) } & \multicolumn{2}{|c|}{ Statistical significance } \\
\hline & Mean & SD & $95 \% \mathrm{CI}$ & Mean & SD & $95 \% \mathrm{CI}$ & "t" & "p" \\
\hline $30 \mathrm{wk}$ & 1.08 & 0.07 & $1.05-1.10$ & 1.10 & 0.07 & $1.08-1.12$ & 1.580 & 0.117 \\
\hline 33 wk & 1.02 & 0.05 & $1.00-1.03$ & 1.12 & 0.06 & $1.10-1.13$ & 8.882 & $<0.001$ \\
\hline $36 \mathrm{wk}$ & 0.97 & 0.04 & $0.95-0.98$ & 1.13 & 0.06 & $1.11-1.14$ & 13.790 & $<0.001$ \\
\hline 39 wk & 0.96 & 0.03 & $0.95-0.97$ & 1.14 & 0.06 & $1.12-1.15$ & 16.819 & $<0.001$ \\
\hline Correlation with time & $r=-0.669$ & & & $\mathrm{r}=0.21 \mathrm{C}$ & & & Overall & \\
\hline
\end{tabular}

The mean HC/AC ratio was higher in FGR group as compared to non-FGR group at all the time intervals (Table 4). However, a significant difference between two groups was seen from 33 weeks onwards.

It was seen that in non-FGR group, the mean $\mathrm{HC} / \mathrm{AC}$ ratio showed a regular decrease from 30 weeks $(1.08 \pm 0.07 ; 95 \%$ CI $1.05-1.10)$ to 39 weeks $(0.96 \pm 0.03$; 95\% CI 0.95-0.97), however, in FGR group a regular increase was seen from 30 weeks $(1.10 \pm 0.07$; 95\% CI $1.08-1.12)$ to 39 weeks $(1.14 \pm 0.06 ; 95 \%$ CI $1.12-1.15)$. In FGR group the mean $\mathrm{HC} / \mathrm{AC}$ ratio was found to be above
1 at all the time intervals whereas in non-FGR group at 30 and 33 weeks it was found to be above 1 and from 36 weeks onwards its value was below 1 . Overall an almost negligible negative correlation $(\mathrm{r}=-0.081)$ in $\mathrm{HC} / \mathrm{AC}$ ratio and gestational age was seen.

However, in non-FGR group this correlation was moderately negative ( $\mathrm{r}=-0.669)$ while in FGR group this was very mild and positive $(\mathrm{r}=0.219)$. The receiver operator curve analysis for detection of FGR was performed. As the mean values were different at different time intervals, four cut-off values were explored at different time intervals (Table 5).

Table 5: Receiver operator curve analysis to find out appropriate cut-off of HC/AC ratio for FGR detection.

\begin{tabular}{|llllll|} 
Time & Area & $\begin{array}{l}\text { Std. Error } \\
\text { (a) }\end{array}$ & $\begin{array}{l}\text { Asymptotic Sig. } \\
\text { (b) }\end{array}$ & \multicolumn{2}{c|}{ Asymptotic 95\% confidence interval } \\
\hline $30 \mathrm{wk}$ & 0.598 & 0.061 & 0.106 & 0.478 & 0.718 \\
\hline $33 \mathrm{wk}$ & 0.919 & 0.029 & $<0.001$ & 0.863 & 0.975 \\
\hline $36 \mathrm{wk}$ & 0.991 & 0.008 & $<0.001$ & 0.976 & 1.006 \\
\hline $39 \mathrm{wk}$ & 0.999 & 0.001 & $<0.001$ & 0.997 & 1.002 \\
\hline
\end{tabular}

a. Under the nonparametric assumption; $\mathrm{b}$. Null hypothesis: true area $=0.5$ 
The area under curve was found to be ranging from 0.598 (30 weeks) to 0.999 (39 weeks). The maximum value was obtained at 39 weeks.

As the area under curve at 30 weeks provided only a limited diagnostic efficacy, it was not explored further. At 33 weeks, the cut-off value above 1.075 indicated $80 \%$ sensitivity and $85.7 \%$ specificity.

At 36 weeks, the cut-off value above 1.045 was $96.9 \%$ sensitive and $100 \%$ specific and at 39 weeks the cut-off value above 1.025 was found to be $98.5 \%$ sensitive and $100 \%$ specific.

As most of the studies have mentioned a cut-off value above 1 from 36 weeks onwards the diagnostic efficacy of $\mathrm{HC} / \mathrm{AC}$ ratio was assessed for this value.
Table 6: Diagnostic efficacy of $\mathrm{HC} / \mathrm{AC}$ ratio as a marker of FGR (Cut-off 1 at 36 week).

\begin{tabular}{|c|c|c|c|c|}
\hline \multirow{2}{*}{$\begin{array}{l}\text { HC/AC Ratio } \\
>1\end{array}$} & \multicolumn{3}{|c|}{ Outcome } & \multirow[b]{2}{*}{ Total } \\
\hline & $\begin{array}{l}\text { FGR } \\
(n=65)\end{array}$ & \multicolumn{2}{|c|}{$\begin{array}{l}\text { No FGR } \\
(n=35)\end{array}$} & \\
\hline Positive & 64 & \multicolumn{2}{|l|}{6} & 70 \\
\hline Negative & 1 & \multicolumn{2}{|c|}{29} & 30 \\
\hline Total & 65 & \multicolumn{2}{|c|}{35} & 100 \\
\hline Sensitivity & Specificity & PPV & NPV & $\begin{array}{l}\text { Diagnostic } \\
\text { Accuracy }\end{array}$ \\
\hline 98.5 & 82.9 & 91.4 & 96.7 & 93.0 \\
\hline
\end{tabular}

$\mathrm{HC} / \mathrm{AC}$ ratio $>1$ at 36 weeks showed to be $98.5 \%$ sensitive and $82.9 \%$ specific with a positive predictive value of $91.4 \%$ and negative predictive value of $96.7 \%$. Overall diagnostic accuracy was found to be $93 \%$ (Table $6)$.

Table 7: FL/AC ratio in two groups at different time intervals.

\begin{tabular}{|c|c|c|c|c|c|c|c|c|}
\hline \multirow{2}{*}{ Time interval } & \multicolumn{3}{|c|}{ Non-FGR Group (n=35) } & \multicolumn{3}{|c|}{ FGR Group (n=65) } & \multicolumn{2}{|c|}{ Statistical significance } \\
\hline & Mean & SD & $95 \% \mathrm{CI}$ & Mean & $\mathrm{SD}$ & $95 \% \mathrm{CI}$ & "t" & "p" \\
\hline $30 \mathrm{wk}$ & 22.89 & 2.20 & $22.13-23.64$ & 23.94 & 2.40 & $23.35-24.54$ & 2.158 & 0.033 \\
\hline 33 wk & 22.91 & 2.44 & $22.07-23.74$ & 24.05 & 2.77 & $23.36-24.73$ & 2.046 & 0.043 \\
\hline 36 wk & 23.01 & 2.66 & $22.09-23.92$ & 24.07 & 2.66 & $23.37-24.77$ & 1.828 & 0.071 \\
\hline 39 wk & 23.06 & 2.61 & $22.16-23.96$ & 24.17 & 3.07 & 23.41-24.94 & 1.818 & 0.072 \\
\hline Correlation with time & $\mathrm{r}=0.02$ & & & $\mathrm{r}=0.02$ & & & $\mathrm{r}=0.02$ & \\
\hline
\end{tabular}

Statistically, a significant difference between two groups was seen for mean FL/AC ratio at 30 weeks and 33 weeks time intervals (Table 7). At 36 weeks and 39 weeks intervals there was no significant difference between the two groups. A very mild (almost negligible) positive correlation between gestational age and mean FL/AC was seen in both the groups. Calculation of cutoff point through receiver operator curve analysis has been shown in Table 8 .

Table 8: Receiver operator curve analysis to find out appropriate cut-off of FL/AC ratio for FGR detection.

\begin{tabular}{|llllll|}
\hline Time & Area & Std. Error(a) & $\begin{array}{l}\text { Asymptotic } \\
\text { Sig.(b) }\end{array}$ & \multicolumn{2}{l|}{$\begin{array}{l}\text { Asymptotic 95\% Confidence Interval } \\
\text { Lower }\end{array}$} \\
\hline 30 wk & 0.632 & 0.057 & 0.030 & 0.520 & 0.744 \\
\hline 36 wk & 0.633 & 0.058 & 0.029 & 0.520 & 0.746 \\
\hline 39 wk & 0.628 & 0.058 & 0.035 & 0.513 & 0.742 \\
\hline
\end{tabular}

a. Under the nonparametric assumption; $b$. Null hypothesis: true area $=0.5$

The area under curve ranged to be 0.628 (36 week) to 0.633 (33 week), thereby showing a very poor association. At 30 weeks the cut-off value $>23.05$ was regressed to be $58.5 \%$ sensitive and $57.1 \%$ specific. At 33 weeks same efficacy was seen at cut-off of 23.17 while at 36 weeks this value was found to be 23.47 and at 39 weeks it was 23.35. None of the choices showed a good diagnostic accuracy.
For the purpose of calculation of diagnostic efficacy, the cut-off value of 23.50 at 36 weeks was chosen.

The FL/AC ratio $>23.5$ was found to be $58.5 \%$ sensitive, $60 \%$ specific and had a PPV of $73.1 \%$ and a NPV of $43.8 \%$ (table 9 and graph 3). Overall diagnostic accuracy of the test was only $59 \%$. 
Table 8: Receiver operator curve analysis to find out appropriate cut-off of FL/AC ratio for FGR detection.

\begin{tabular}{|c|c|c|c|c|}
\hline \multirow{2}{*}{$\begin{array}{l}\text { FL/AC Ratio } \\
>23.5\end{array}$} & \multicolumn{3}{|c|}{ Outcome } & \multirow[b]{2}{*}{ Total } \\
\hline & $\begin{array}{l}\text { FGR } \\
(n=65)\end{array}$ & \multicolumn{2}{|c|}{$\begin{array}{l}\text { No FGR } \\
(n=35)\end{array}$} & \\
\hline Positive & 38 & \multicolumn{2}{|c|}{14} & 52 \\
\hline Negative & 27 & \multicolumn{2}{|c|}{21} & 48 \\
\hline Total & 65 & \multicolumn{2}{|c|}{35} & 100 \\
\hline Sensitivity & Specificity & PPV & NPV & $\begin{array}{l}\text { Diagnostic } \\
\text { Accuracy }\end{array}$ \\
\hline 58.5 & 60.0 & 73.1 & 43.8 & 59.0 \\
\hline
\end{tabular}

\section{DISCUSSION}

Fetal growth restriction (FGR) is a condition in which fetus does not reach its growth potential. ${ }^{5}$ The present study was conducted at a tertiary care centre in Lucknow which was attended by patients from both rural and urban segments. Gray scale ultrasound parameters studied were TCD/AC ratio, HC/AC ratio and FL/AC ratio.

On Gray scale analysis, a statistically significant difference between study and control group was observed for TCD/AC ratio in both the groups with FGR group showing significantly higher mean value as compared to non-FGR group. At 30 weeks TCD/AC ratio with cut-off $>14.18$ was found to be $81.5 \%$ sensitive and $68.6 \%$ specific.

In the study of Haller et al TCD/AC ratio showed a poor correlation with gestational age $(\mathrm{r} 2=0.15788)$ and a slight increase was noted during gestation. ${ }^{6}$ In present study too, a poor correlation $(\mathrm{r}=0.028)$ was seen between $\mathrm{TCD} / \mathrm{AC}$ ratio and gestational age. In this study too, a slight increase in TCD/AC ratio was seen from 30 weeks to 39 weeks. Haller et al reported that a TCD/AC ratio greater than 15.5 was present in $80 \%$ of SGA infants when measurements were performed within 1 week of delivery. However, in present study a TCD/AC ratio above 14.18 was found to be having $77 \%$ accuracy in detection of FGR. Thus, present findings are in concurrence with the findings of Haller et al. ${ }^{6}$

In present study it was seen that at all time intervals there was a statistically significant difference in TCD/AC ratio between FGR and non-FGR groups, it was seen that the mean value of TCD/AC ratio in FGR group was always higher to the upper limit of $95 \%$ CI of non-FGR group. Campbell et $\mathrm{al}^{7}$ have reported the mean TCD/AC ratio to be $13.7 \%$ (fifth and 95th percentiles of 11.9 and $15.9 \%$, respectively. They have found that this ratio was gestational age-independent and have applications in assessment of fetal growth rate. In the present study $\mathrm{TCD} / \mathrm{AC}$ ratio was found to be $81.5 \%$ sensitive in detection of FGR, however, in the study of Ott $\mathrm{W},{ }^{8}$

$\mathrm{TCD} / \mathrm{AC}$ ratios were reported to be only $53 \%$ sensitive in predicting IUGR. Thus, present results are in consistence with the results of Tongsong et al who reported that the best cut-off value of the TCD/AC ratio for predicting IUGR was $15.4 \%$, giving the sensitivity, specificity, positive predictive value and negative predictive value of $73.26 \%, 80.25 \%, 79.75 \%$, and $73.86 \%$, respectively. ${ }^{9}$ Though the cut-off value obtained in the present study was $14.18 \%$, yet it was able to provide a good diagnostic accuracy. Though the incidence of higher false positivity affected the specificity and negative predictive value to some extent in present study. The mean HC/AC ratio was higher in FGR group as compared to non-FGR group at all the time intervals. However, a significant difference between two groups was seen from 33 weeks onwards.

The mean HC/AC ratio was higher in FGR group as compared to non-FGR group at all the time intervals. However, a significant difference between two groups was seen from 33 weeks onwards. It was seen that in nonFGR group, the mean $\mathrm{HC} / \mathrm{AC}$ ratio showed a regular decrease from 30 weeks $(1.08 \pm 0.07 ; 95 \%$ CI $1.05-1.10)$ to 39 weeks $(0.96 \pm 0.03 ; 95 \%$ CI $0.95-0.97)$, however, in FGR group a regular increase was seen from 30 weeks $(1.10 \pm 0.07 ; 95 \%$ CI $1.08-1.12)$ to 39 weeks $(1.14 \pm 0.06$; $95 \%$ CI 1.12-1.15).

In FGR group the mean HC/AC ratio was found to be above 1 at all the time intervals whereas in non-FGR group at 30 and 33 weeks it was found to be above 1 and from 36 weeks onwards its value was below 1 . With time a moderately negative correlation between RI and gestational age was observed $(\mathrm{r}=-0.669)$ in non-FGR group while in FGR group this was very mild and positive $(\mathrm{r}=0.219)$.

$\mathrm{HC} / \mathrm{AC}$ ratio $>1$ at 36 weeks showed to be $98.5 \%$ sensitive and $82.9 \%$ specific with a positive predictive value of $91.4 \%$ and negative predictive value of $96.7 \%$. Overall diagnostic accuracy was found to be $93 \%$.

In a non-FGR normal pregnancy the $\mathrm{HC} / \mathrm{AC}$ ratio is $>1.0$ prior to 36 weeks however, with increase in gestational age the ratio shows a decrease. In FGR pregnancy, this ratio either does not change or shows increment. ${ }^{10}$ In present study, we found similar patterns. At 30 and 33 weeks, the mean $\mathrm{HC} / \mathrm{AC}$ ratio in both FGR and non-FGR groups was above 1 .

However, on 36 weeks and 39 weeks, the mean HC/AC ratio in non-FGR group was found to be less than 1 while in FGR group, it was seen to be above 1. According to Peleg et al between 20 and 36 weeks of gestation, the $\mathrm{HC} / \mathrm{AC}$ ratio normally drops almost linearly from 1.2 to 1.0. ${ }^{11}$ The ratio is normal in the fetus with symmetric growth restriction and elevated in the fetus with asymmetric growth restriction. In a study by Blackwell et al, the asymmetric-IUGR group had $\mathrm{HC} / \mathrm{AC} \geq 95 \%$ tile for GA, and the symmetric-IUGR group had HC/AC $<95 \%$ tile. $^{12}$

In present study too, at all time intervals the upper limit of $95 \%$ confidence interval in non-FGR group was either 
equal (at 33 weeks) or below (at all the other time intervals) the mean value of $\mathrm{HC} / \mathrm{AC}$ ratio in the FGR group. Thus $\mathrm{HC} / \mathrm{AC}$ ratio in present study was found to be a significant predictor of FGR. In the study of Hebbar et al a statistically significant difference in $\mathrm{HC} / \mathrm{AC}$ ratio of non-FGR and growth restricted group was seen with non-FGR group showing a significantly lower value as compared to $\mathrm{HC} / \mathrm{AC}$ ratio. ${ }^{13}$

Present results are in accordance with their findings. In their study they had found a cut-off value of 1.02 to be $67 \%$ sensitive, $65 \%$ specific with a PPV of $54 \%$ and NPV of $76 \%$. However, in our study the cut-off value of 1 was found to be $98.5 \%$ sensitive, $82.9 \%$ specific, with a PPV of $91.4 \%$ and an NPV of $96.7 \%$. Thus, results in present study were found to be provide diagnostic more accurate information as compared to the other studies. The study of Jasovic-Siveska et al showing HC/AC ratio at different gestational ages showed it to be significantly higher in gross IUGR group as compared to that in low IUGR group at 26, 32, 36 and 38 weeks of gestational age. ${ }^{14}$ In present study, except for 30 weeks, at all the time intervals the mean $\mathrm{HC} / \mathrm{AC}$ ratio of FGR group was significantly higher as compared to non-FGR group.

Statistically, a significant difference between two groups was seen for mean FL/AC ratio at 30 weeks and 33 weeks time intervals. At 36 weeks and 39 weeks intervals there was no significant difference between the two groups. A very mild (almost negligible) positive correlation between gestational age and mean FL/AC was seen in both the groups which is not statistically significant. The FL/AC ratio >23.5 at 36 weeks was found to be $58.5 \%$ sensitive, $60 \%$ specific and had a PPV of $73.1 \%$ and an NPV of $43.8 \%$. Overall diagnostic accuracy of the test was only $59 \%$.

Benson et al have shown FL/AC ratio to be a poor prognostic indicator of IUGR. ${ }^{15}$ They reported that with a cut-off of 23.5, the sensitivity was $56 \%$ and the specificity $74 \%$. In present study, the cutoff of 23.5 showed to be $58.5 \%$ sensitive, $60 \%$ specific and had a PPV of $73.1 \%$ and a NPV of $43.8 \%$, thus confirming the findings of Benson et al. ${ }^{15} \mathrm{Ott} \mathrm{WJ}$ and Shalev E et al have used cut-off varying from $24 \%$ to $27 \%$ but showed a very low sensitivity. ${ }^{8,16}$ However, in the study of Hebbar et al, FL/AC ratio above $24 \%$ was found to be $77 \%$ sensitive, $73 \%$ specific and having $64 \%$ PPV and $84 \%$ NPV. ${ }^{13}$ The high variability in selection of a cut-off and its diagnostic efficacy act as a deterrent for broader use of FL/AC ratio as a diagnostic test for detection of FGR.

The findings in present study suggested that while Gray scale ultrasound provide maximum efficacy at 36 week gestational age (HC/AC and FL/AC ratio) though TCD/AC ratio showed a promising efficacy at 30 weeks gestational age itself. Thus, it was observed that both gray scale ultrasound for all parameters and resistive index of uterine artery and umbilical artery both showed a promising utility as a diagnostic marker for FGR.

\section{CONCLUSION}

Among three gray scale parameters being assessed, $\mathrm{HC} / \mathrm{AC}$ ratio at 36 weeks was observed to be having $98.5 \%$ sensitivity and $82.9 \%$ specificity, thus showing the highest diagnostic accuracy (93\%). However, from the point of view of early detection, TCD/AC ratio was found to be most efficient with $81.5 \%$ sensitivity and $68.6 \%$ specificity and overall diagnostic accuracy of $77 \%$.

\section{Funding: No funding sources}

Conflict of interest: None declared

Ethical approval: The study was approved by the Institutional Ethics Committee

\section{REFERENCES}

1. Patre V, Aryan AK, Sahu P, Patre V. Ultrasonographic evaluation of fetal humerus length for assessment of gestational age and its comparison with other conventional parameters. Int $\mathrm{J}$ Scient Study. 2015 Oct 1;3(7):58-64.

2. Baschat AA. Pathophysiology of fetal growth restriction: implications for diagnosis and surveillance. Obstet Gynecol Surv. 2004 Aug 1;59(8):617-27.

3. Allen MC. Developmental outcome and follow up of the small for gestational age infant. Semin Perinatol. 1984;8:123-56.

4. Cunninghum FG, Leveno KJ, Bloom SL. Williams Obstetrics, 22nd Edition. Mc Graw Hill, Medical Publishing Division; 2005:900.

5. Alberry M, Soothill P. Management of fetal growth restriction. Archives of Disease in Childhood-Fetal and Neonatal Edition. 2007 Jan 1;92(1):F62-7.

6. Haller H, Petrovic O, Rukavina B. Fetal transverse cerebellar diameter/abdominal circumference ratio in assessing fetal size. Int J Gyncol Obstet. 1995;50(2): 159-63.

7. Campbell WA, Nardi D, Vintzileos AM, Rodis JF, Turner GW, Egan JF. Transverse cerebellar diameter/abdominal circumference ratio throughout pregnancy: a gestational age-independent method to assess fetal growth. Obstet Gynecol. 1991 Jun;77(6):893-6.

8. Ott W. An update in the ultrasonic diagnosis and evaluation of intrauterine growth restriction. The Ultrasound Rev Obstet Gynecol. 2005;5(2):111-24.

9. Tongsong $\mathrm{T}$, Wanapirak $\mathrm{C}$, Thongpadungroj $\mathrm{T}$. Sonographic diagnosis of intrauterine growth restriction (IUGR) by fetal transverse cerebellar diameter (TCD)/abdominal circumference (AC) ratio. Int J Gyncol Obstet. 1999;66(1):1-5.

10. Blickstein I, Keith LG, editors. Multiple pregnancy: epidemiology, gestation, and perinatal outcome. CRC Press; 2005 Mar: 516.

11. Peleg D, Kennedy CM, Hunter SK. Intrauterine growth restriction: identification and management. American family physician. 1998 Aug;58(2):453-60. 
12. Blackwell SC, Moldenhaeur J, Redman M, Hassan SS, Wolfe HM and Berry SM. Relationship between the sonographic pattern of intrauterine growth restriction and acid-base status at the time of cordocentesis. Arch Gynecol Obstet. 2001;264(4):191-3

13. Hebbar S, Varalakshmi N. Comparison of three ultrasound ratios in term low birth weight babies - is there a role for thigh circumference? Calicut Med J. 2007;5(3)e1.

14. Jasovic-Siveska EI, Jasovic VI. Real-time ultrasound in detection of intrauterine growth retardation in preeclampsia. Bratisl Lek Listy. 2008;109(9):405-11.
15. Benson CB, Doubilet PM, Saltzman DH, Jones TB. FL/AC ratio: poor predictor of intrauterine growth retardation. Invest Radiol. 1985 Oct;20(7):727-30.

16. Shalev E, Blondheim O, Peleg D. Use of cordocentesis in the management of preterm or growth-restricted fetuses with abnormal monitoring. Obstet Gynecol Surv. 1995;50:839-44.

Cite this article as: Chakarvarty N, Srivastav K, Khanduri S. A study to evaluate a correlation between various Gray Scale parameters and period of gestation. Int J Reprod Contracept Obstet Gynecol 2018;7:2434-40. 